\title{
Correction to: Can Pharmacokinetic Studies Assess the Pulmonary Fate of Dry Powder Inhaler Formulations of Fluticasone Propionate?
}

\author{
Günther Hochhaus $^{1,14} \cdot$ Mong-Jen Chen $^{1,2} \cdot$ Abhinav Kurumaddali $^{1} \cdot$ Uta Schilling $^{1} \cdot$ Yuanyuan Jiao $^{3}$. \\ Stefanie K. Drescher ${ }^{1} \cdot$ Elham Amini $^{1} \cdot$ Simon M. Berger $^{1} \cdot$ Bhargava Kandala $^{1} \cdot$ Christine Tabulov $^{1}$. \\ Jie Shao ${ }^{1} \cdot$ Brandon Seay $^{4} \cdot$ Mutasim N. Abu-Hasan $^{4} \cdot$ Sandra M. Baumstein $^{3} \cdot$ Lawrence Winner $^{5}$. \\ Jagdeep Shur $^{6} \cdot$ Robert Price $^{6} \cdot$ Michael Hindle $^{7} \cdot$ Xiangyin Wei $^{7} \cdot$ Cynthia Carrasco $^{8} \cdot$ Dennis Sandell $^{9}$. \\ Oluwamurewa Oguntimein $^{10} \cdot$ Minori Kinjo $^{10} \cdot$ Renishkumar Delvadia $^{10,11} \cdot$ Bhawana Saluja $^{10,12} \cdot$ Sau L. Lee $^{13}$. \\ Denise S. Conti ${ }^{10} \cdot$ Jürgen B. Bulitta $^{3,14}$
}

published online 22 November 2021

Correction to: The AAPS Journal volume 23, Article number: 48 (2021)

https://doi.org/10.1208/s12248-021-00569-X

In this article, Simon M. Berger at affiliation Department of Pharmaceutics, College of Pharmacy, University of Florida, 1345 Center Drive, Gainesville, Florida, 32610, USA, was missing from the author list.

Publisher's Note Springer Nature remains neutral with regard to jurisdictional claims in published maps and institutional affiliations.
The original article can be found online at

https://doi.org/10.1208/s12248-021-00569-x.

${ }^{1}$ Department of Pharmaceutics, College of Pharmacy, University of Florida, 1345 Center Drive, Gainesville, FL 32610, USA

2 AbbVie Inc., North Chicago, IL, USA

3 Department of Pharmacotherapy and Translational Research, College of Pharmacy, University of Florida, 6550 Sanger Road, Orlando, FL 32827-7445, USA

${ }^{4}$ Division of Pediatric Pulmonary and Sleep Medicine, Department of Pediatrics, College of Medicine, University of Florida, Gainesville, FL, USA

5 Department of Statistics, College of Liberal Arts \& Sciences, University of Florida, Gainesville, FL, USA

${ }^{6}$ Department of Pharmacy \& Pharmacology, Centre for Therapeutic Innovation, University of Bath, Bath, UK

7 Department of Pharmaceutics, Virginia Commonwealth University, Richmond, VA, USA

${ }^{8}$ Worldwide Clinical Trials, Austin, TX, USA

${ }^{9}$ S5 Consulting, Blentarp, Sweden

\section{aล口}

${ }^{10}$ Office of Research and Standards, Office of Generic Drugs, Center for Drug Evaluation and Research, US Food and Drug Administration, Silver Spring, MD, USA

${ }^{11}$ Office of New Drug Products, Office of Pharmaceutical Quality, Center for Drug Evaluation and Research, US Food and Drug Administration, Silver Spring, MD, USA

12 Office of Clinical Pharmacology, Office of Translational Sciences, Center for Drug Evaluation and Research, US Food and Drug Administration, Silver Spring, MD, USA

13 Office of Testing and Research, Office of Pharmaceutical Quality, Center for Drug Evaluation and Research, US Food and Drug Administration, Silver Spring, MD, USA

14 To whom correspondence should be addressed. (e-mail: hochhaus@ufl.edu; jbulitta@cop.ufl.edu) 